\title{
THE PHYSIOLOGIC SIGNIFICANCE OF THE BABINSKI TOE RESPONSE *
}

\author{
I. LEON MEYERS, M.D.
}

Attending Neurologist, Cook County Hospital

CHICAGO

The abnormal plantar response that occurs in disease of the pyramidal tract, as described by Babinski, ${ }^{1}$ consists of a group of simultaneously occurring movements, the most conspicuous of which are dorsiflexion of the big toe, separation-generally associated with plantar flexion of the other toes and eversion of the foot. The reflexes with which the phenomenon should properly be identified are, therefore, the coordinate or purposive reflexes. These reflexes, in addition to exhibiting themselves in simultaneous contraction of a large number of muscles, are like the Babinski response in that they occur exclusively or are especially prominent after the cerebral influence has been removed. Sherrington ${ }^{2}$ and Riddoch ${ }^{3}$ give details concerning these reflexes in the "spinal" animal and "spinal" man.

\section{PREVIOUS INTERPRETATIONS OF THE BABINSKI TOE RESPONSE}

Among the explanations of the origin and mechanism of the toe response are: Knapp ${ }^{4}$ attributed the dorsiflexion of the big toe to a greater permeability of the neuron paths of the extensor longus hallucis. Van Woerkom ${ }^{5}$ considered this movement of the big toe a manifestation of a primitive function existing when man, in his evolution, abandoned an arboreal life to lead one of terrestrial progression. Marie and Foix, ${ }^{6}$ noting that with extension of the big toe there is a shortening of the stimulated limb, concluded that the reflex represents the flexion phase of the step, or of the "mark-time" movements of Freusberg, Sherrington and others. They thus consider the Babinski toe response to be the "minimal motor response" of that phase of the step in which the limb is advancing to a new position.

Walshe, ${ }^{7}$ who studied the flexion reflex, flexor spasms and the Babinski toe reflex, maintains that all these phenomena are identical

* Read before the Section on Nervous and Mental Diseases at the SeventyFirst Annual Session of the American Medical Association, New Orleans, April, 1920.

1. Babinski, M. J.: Compt. rend. Soc. de biol., 1897; Semaine méd. 17: 321, 1898.

2. Sherrington, C. S.: J. Physiol. 5:28, 1910.

3. Riddoch, George: Brain 40:264, 1917.

4. Knapp, P. C.: Rev. Neurol. \& Psychiat. 5:825, 1907.

5. Van Woerkom: Rev. Neurol. 22:285, 1912.

6. Marie and Foix: Rev. Neurol. 23:657, 1912.

7. Walshe, F. M. R.: Brain 37:269, 1915. 
in character. The toe response is thus part of that type of flexion reflex which is purely defensive, such as the withdrawal of the limb on the application of a hurtful stimulus. Whereas Marie and Foix look upon the toe response as the "minimal motor response" in the flexion phase of the step, Walshe considers contraction of the hamstring muscle, which occurs synchronously with the toe response, as the "minimal motor response" of the movement of defense.

Any one of these theories is open to the objection that it does not explain the various movements that accompany dorsiflexion of the big toe, such as the fanning out and plantar flexion of the other toes, eversion of the foot and especially contraction of the quadriceps cruris, an extensor of the leg, and contraction of the gluteus maximus, a pure extensor of the thigh. That there is synchronously with the Babinski toe response contraction of the quadriceps cruris has been noted by Cohn, ${ }^{8}$ Jacobsohn and Caro, ${ }^{9}$ Erwin Loewy ${ }^{10}$ and myself.

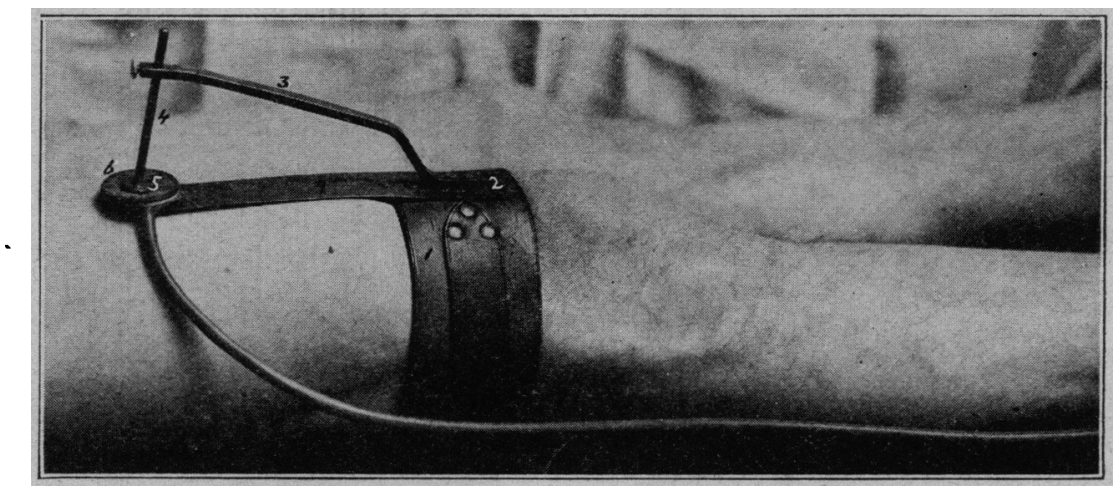

Fig. 1.-Apparatus for recording the movements in the segments of the limbs

But $I$ have also noted that there is simultaneously an extension of the thigh on the hip. The contraction of the gluteus maximus producing this movement can be frequently observed when the toe sign is obtained while the subject is in the prone position. This is shown graphically in Figures 4 and 5.

To obtain these graphic records, I employed this method: A piece of cord attached to the big toe passed under a pulley to a writing lever in contact with the drum of a kymograph. Dorsiflexion of the big toe was thus recorded by an upstroke of the lever. To record the other movements in the limb I employed the apparatus shown in Figure 1.

8. Cohn; T.: Neurol. Centralbl. 30:1107, 1911.

9. Jacobsohn and Caro: Neurol. Centralbl. 31:420, 1912.

10. Loewy, Erwin: Neurol. Centralb1. 32:90, 1913. 

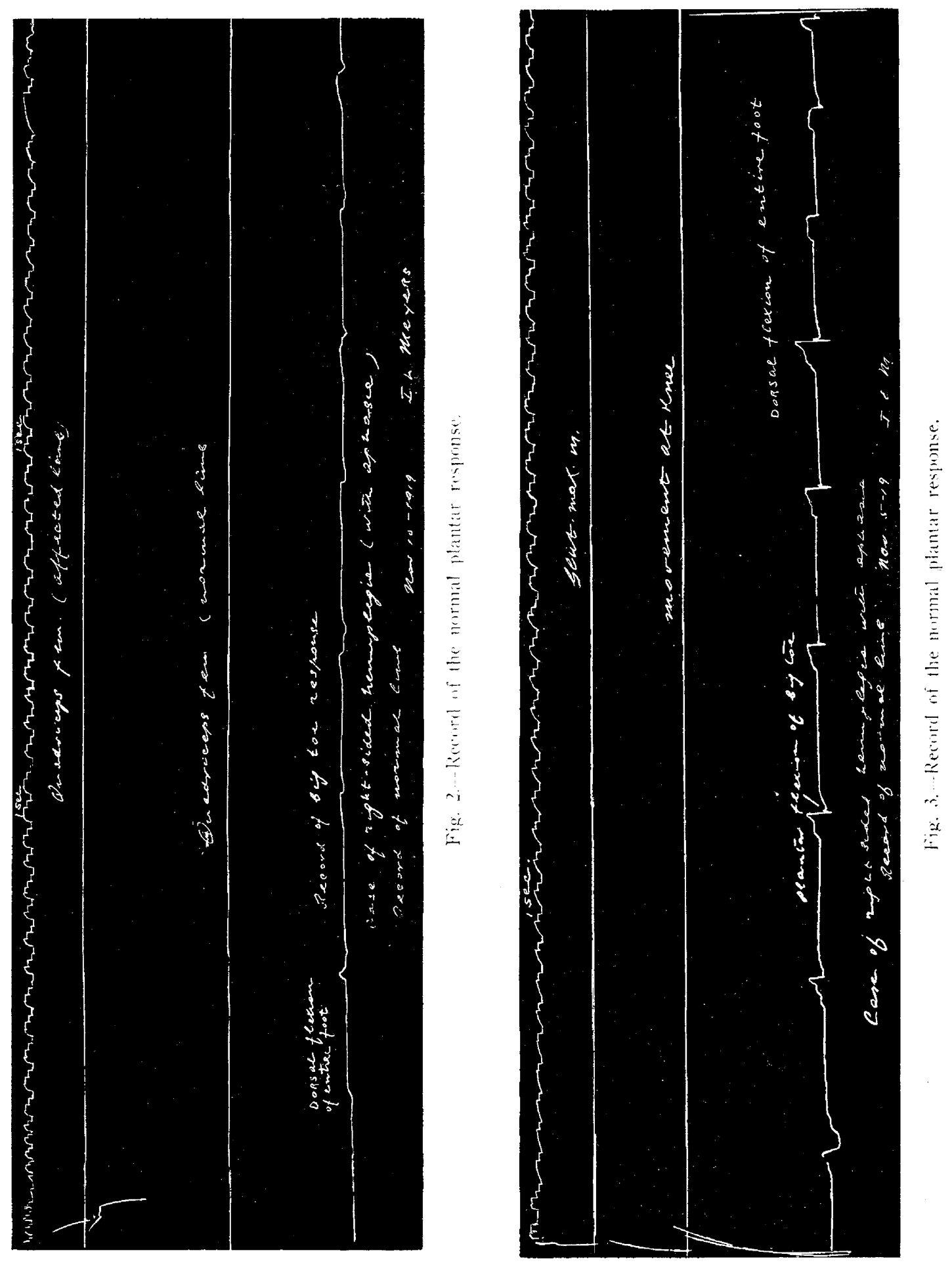

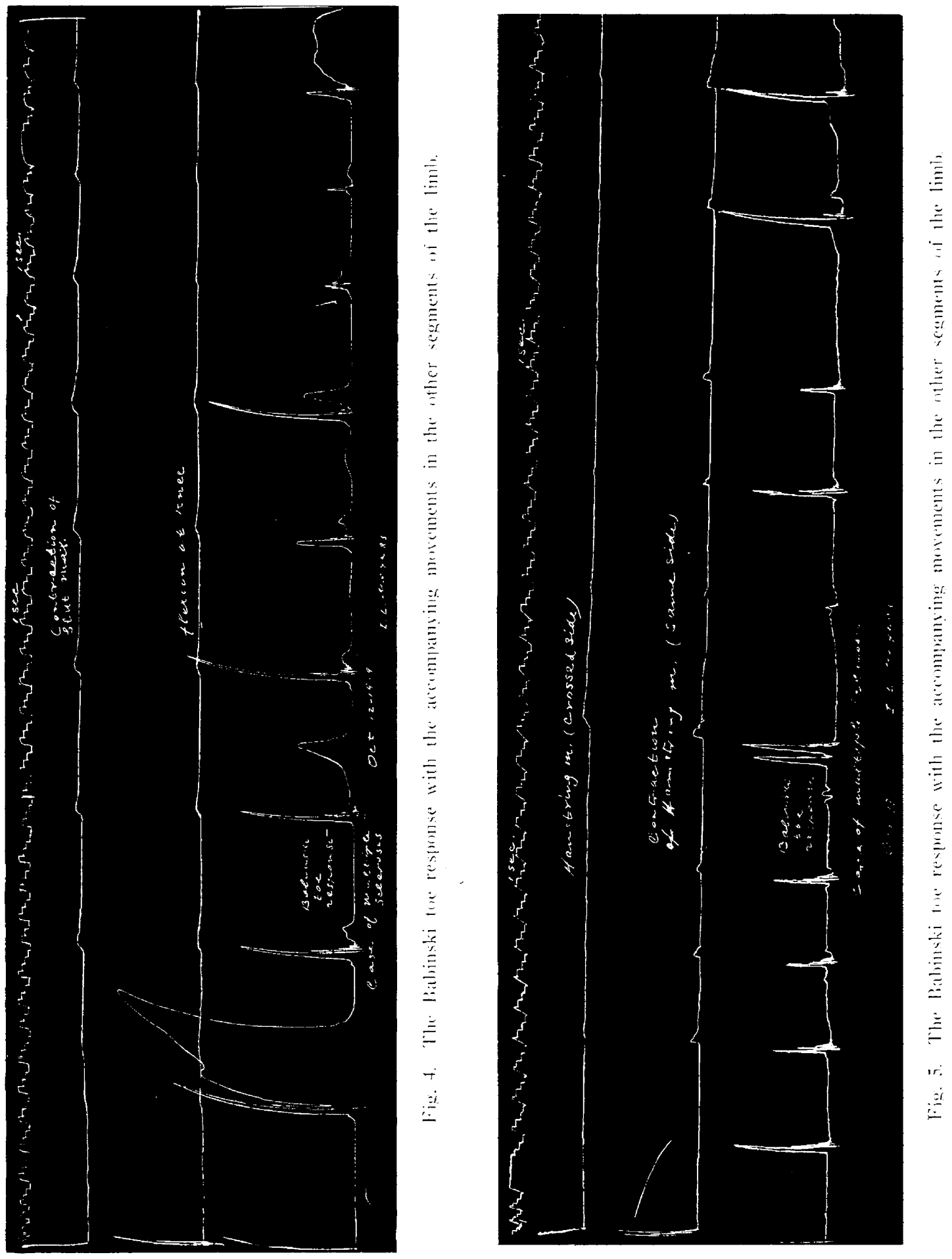

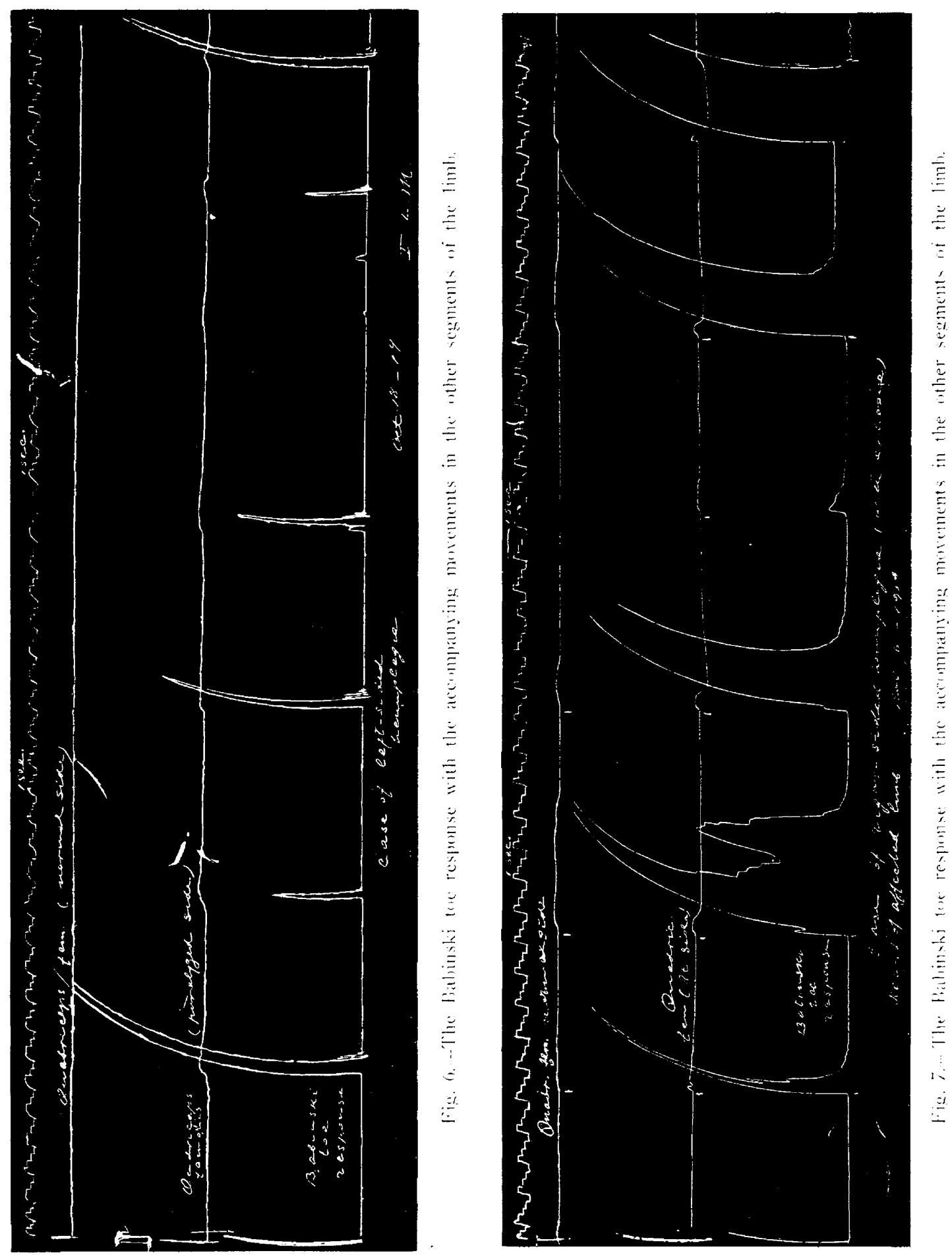
To the middle of a leather braclet (1) is fastened a metal plate (2). To this plate are riveted a semirigid metal strap over 5 inches long (7) which extends along the surface of the limb in its long axis and a rigid bar (3) rising from its point of attachment so that its end is a couple of inches above the free end of the metal strap. Through the free end of the bar passes a metal rod (4) which rests

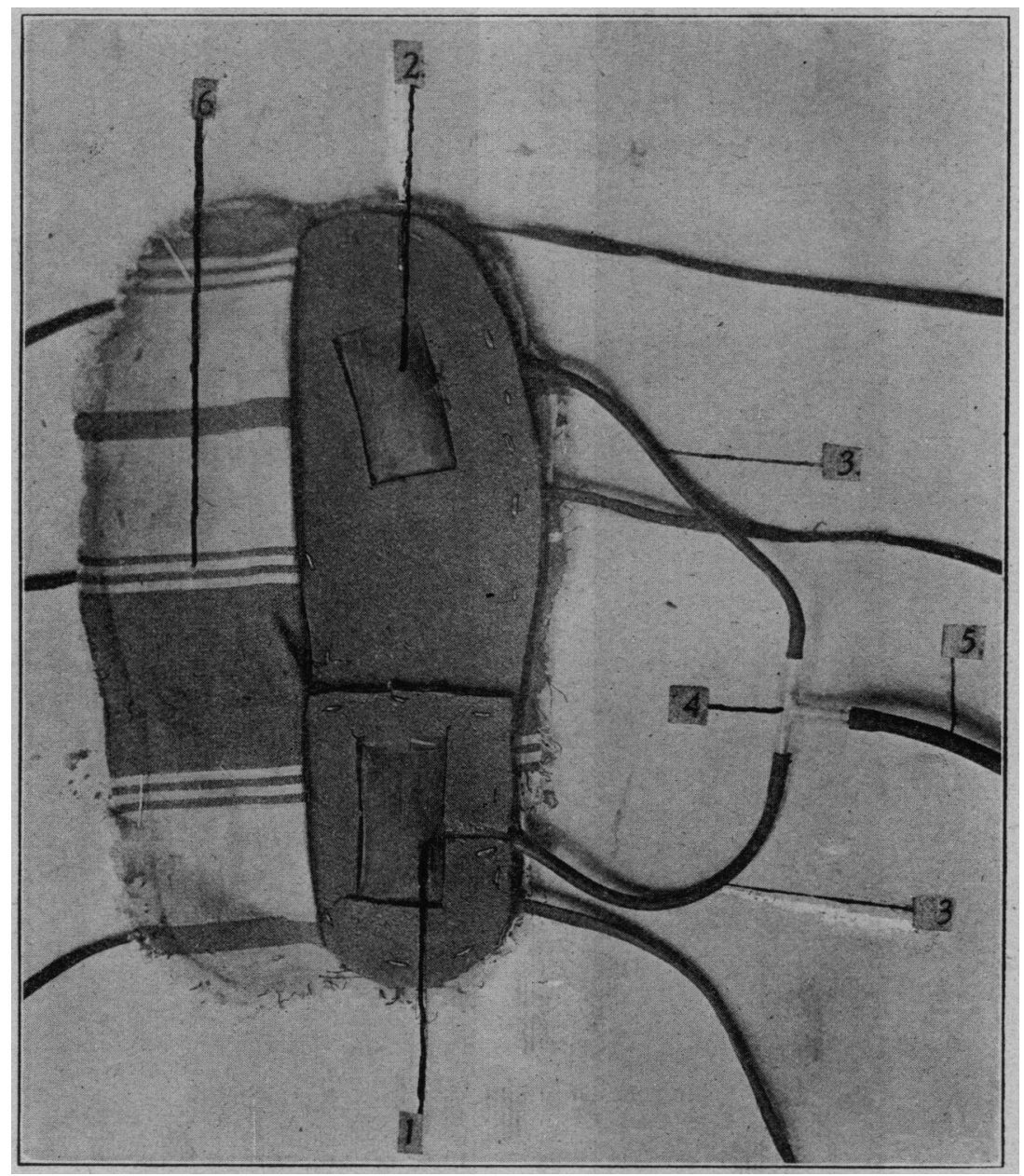

Fig. 8.-Apparatus for recording the movements of the foot in walking.

by a small circular plate (5) on an elastic air chamber (6), fastened to the free end of the metal strap. The rod is secured by a thumb screw where it passes through the bar so that the circular plate is kept firmly in contact with the air chamber. By a rubber tube the air chamber communicates with a Marey's tambour and a kymograph, 


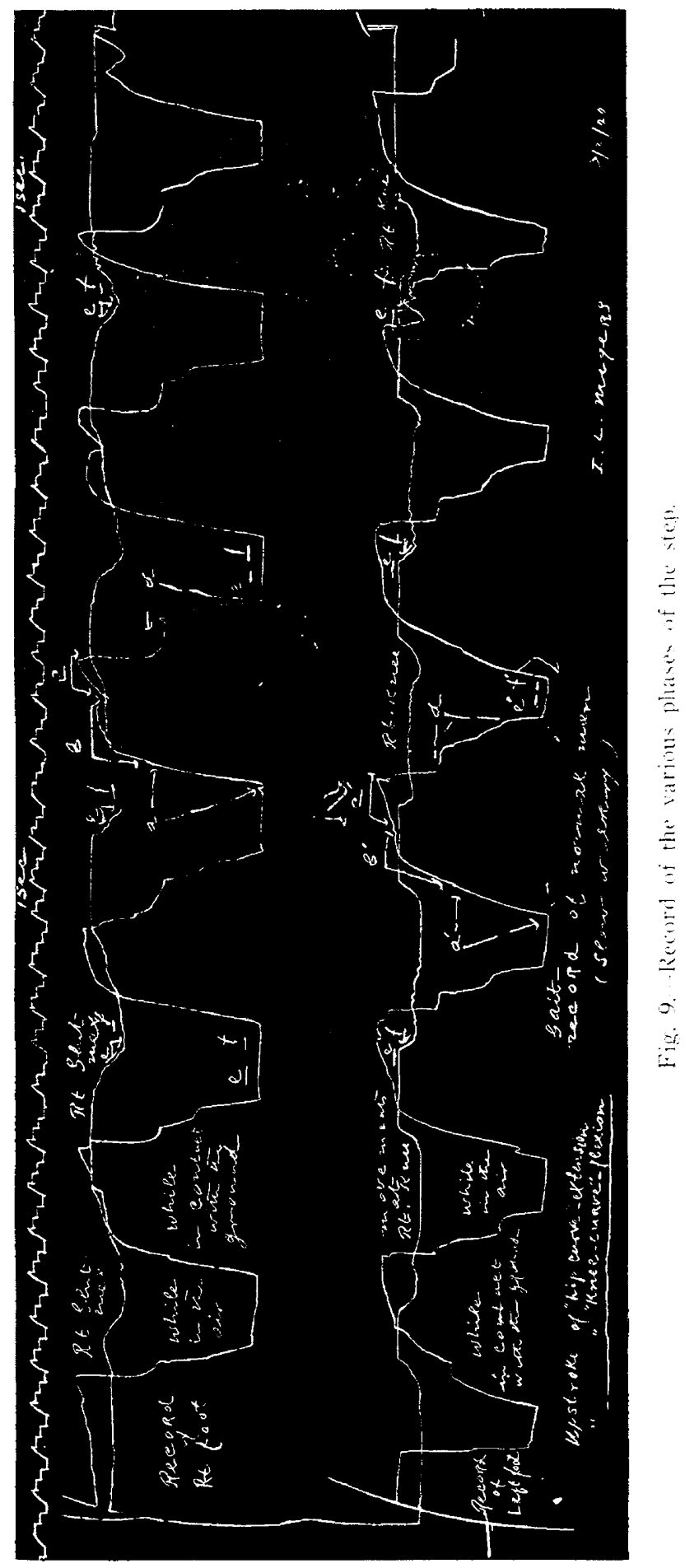


To record the contraction of the quadriceps cruris and the hamstring muscle, the bracelet encircled the thigh at the lower end and the air chamber rested, respectively, at about the middle of the quadriceps or on the hamstring muscles just below the gluteal fold. To record the contraction of the gluteus maximus the bracelet encircled the thigh at about its middle and the air chamber rested on the lower part of the muscle which extends between its origin at the sacrum and coccyx and its insertion. I recorded the flexion of the knee on the thigh by having the bracelet encircle the thigh at about its middle and the air chamber rest at the lower end of the popliteal space between the two heads of the gastrocnemius. I have graphic records of the movements in the limbs associated with the Babinski toe response from fourteen hemiplegic or paraplegic patients. The results obtained are shown in Figures 4 to 7 . The records show that simultaneously with the Babinski toe response there was invariably a contraction of the homolateral quadriceps cruris, gluteus maximus and hamstring muscles. This response was not accompanied by movement in the contralateral thigh (with the exception of slight contraction of the hamstring muscles) when the stimulus was mild. When, however, the stimulus was strong, the contraction of the quadriceps was immediately followed by its relaxation and this was accompanied by contraction of the contralateral quadriceps. In the one case of Friedreich's ataxia I have obtained results in some respects, directly the reverse of the preceding. The records showed that simultaneously with the Babinski toe response there was flexion of the knee with relaxation of the homolateral quadriceps and gluteus maximus (Figs. 11 and 12). This may have been due to the muscular atonia in this disease. In contrast to the response on the paretic side in hemiplegics, was that obtained from the normal limb. When the stimulus was strong the limb underwent a rapid movement of withdrawal. entirely too rapid to be properly recorded; when the stimulus was mild, there was dorsiflexion of the foot, generally immediately followed by plantar flexion of the big toe (the only toe the movements of which were recorded), with no movement in the other segments of the limb) (Figs. 2 and 3 ).

\section{MOVEMENTS OF THE LIMBS IN LOCOMOTION}

Since locomotion is the primary and essential function of the lower limbs, I wished to determine whether this combination of movements occurring synchronously with the Babinski sign is reproduced by the limbs at any time during walking. First $I$ considered that the inner metatarsal, as is shown by a number of anatomic facts, ${ }^{11}$ forms the

11. Frazer, J. Ernest: Anatomy of the Human Skeleton, London, J. A. Churchill, 1914. 

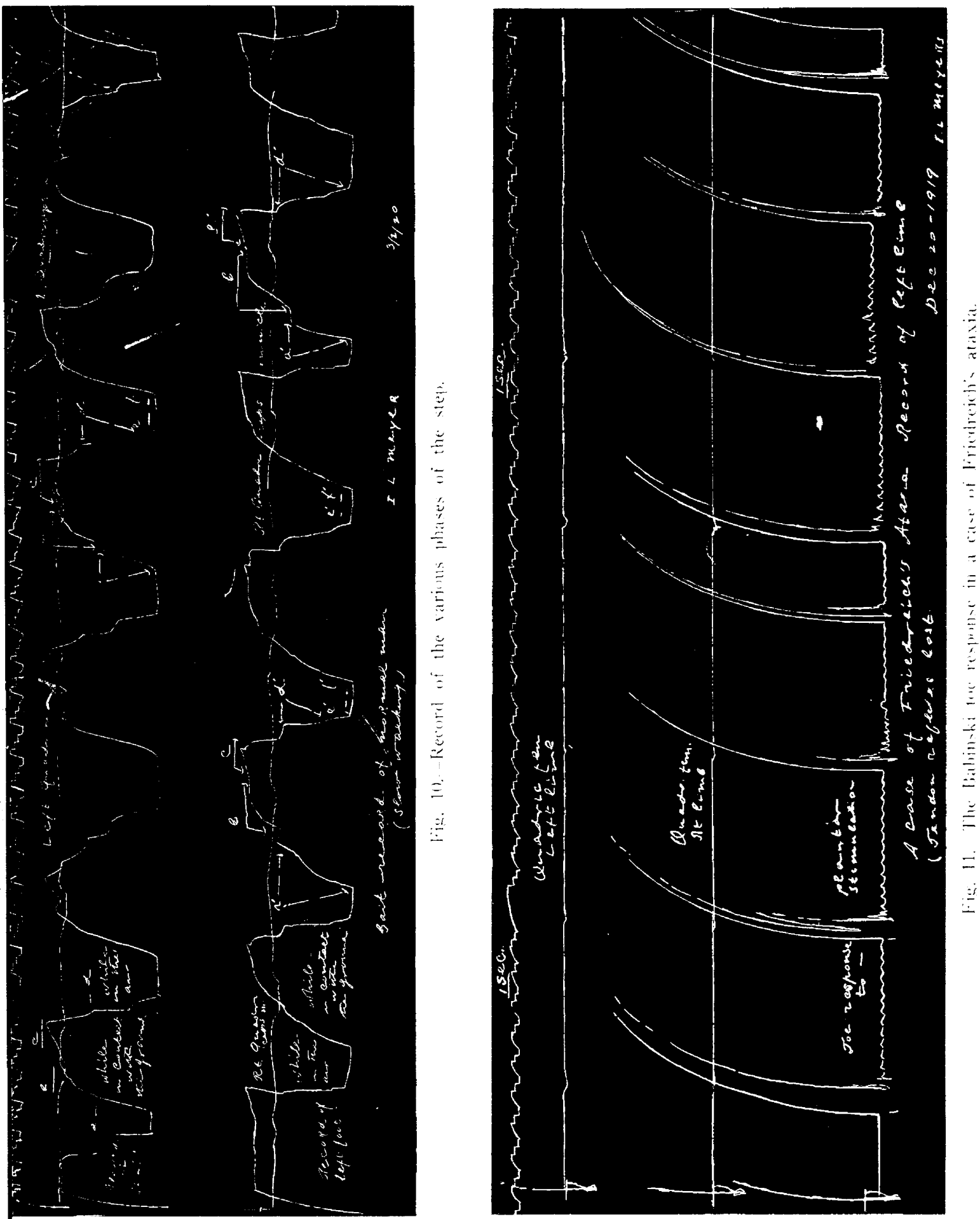
medium through which pressure is exerted on the ground during the propulsion period of the step. The outer metatarsus, with its practically immobile articulations, serves chiefly as a guide and point of support for the body and limb while they are rotating anteriorly during this period of the step. Accordingly I fastened to each foot of a normal person a pneumatic pad, such as I employed in my experiments on the locomotor disturbances in disease of the cerebellum (Fig. 8). The anterior air chamber was placed under the inner metatarsal head instead of the center of the ball of the foot as in my previous studies. Records were thus obtained of the movemients of the foot while in contact with the ground, as well as of the length of time it is in the air. Movements of the other segments of the limbs during each phase of the step were recorded at the same time by means of the apparatus employed for recording the movements that accompany the Babinski sign. The records obtained are shown in Figures 9 and 10. They show: (1) $a$, the upstroke which initiates the high curve of the record. This corresponds to the moment when the foot is deposited on the ground, coming in contact with it by the heel (Pettigrew ${ }^{13}$ ). The resulting compression of the air bulb at the heel causes the lever to become elevated. The associated movements in the other segment of the limbs during this phase of the step are: The hip is slightly extending, the knee is slightly flexing, the quadriceps cruris is contracting and the quadriceps of the contralateral limb, which is at this moment exerting pressure on the ground by the toes, (phase $d^{\prime}$ ) is relaxing. (2) Immediately following $a$, phase $b$ sets in, which is but a continuation of $a$. During this phase $(b)$ the whole foot comes in contact with the ground, especially at the heel. The associated movements in the other segments of the limb during this phase are the same as in $a$, except that the extension at the hip is here greatly intensified. The position of the limb is now to a minor degree, similar to that assumed by the limbs at the beginning of a jump, when in order to exert great and rapid pressure on the ground, they are considerably flexed at the knees. The contraction of the quadriceps during these phases, while the knee is slightly flexing (action of the hamstring muscles) is in accord with the view of Winslow, ${ }^{14}$ Hunter, ${ }^{14}$ Duchenne ${ }^{15}$ and

12. Meyers, I. Leon: Locomotor Disturbances in Disease of the Cerebellum, Arch. Neurol. \& Psychiat. 2:376 (Oct.) 1919.

13. Pettigrew, J. Bell: Animal Locomotion, New York, Appleton \& Co., 1874, pp. 8 and 9, 56-59; Design in Nature, New York, Longmans, Green \& Co. 3:1077 and 1122, 1908.

14. Winslow, J. B.: Quoted by C. E. Beevor: The Croonian Lectures, London, Adlard and Son, 1904, p. 52.

15. Duchenne, G. B.: Physiologie des Mouvements, 1867, p. 766. 

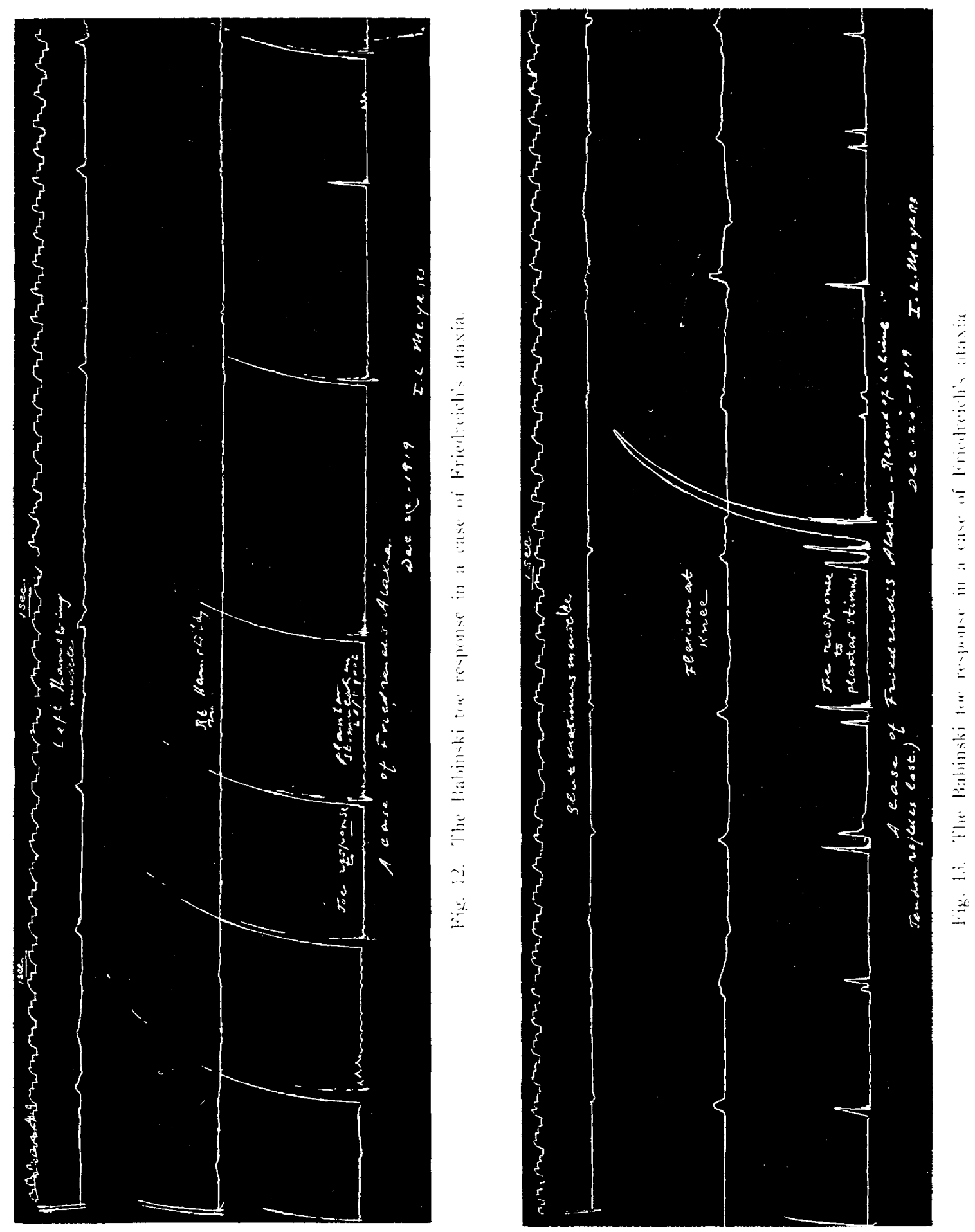
others that in movements that are to be accurate and precise, the antagonists act simultaneously with the protagonists. (3) Phase $c$, the pressure on the ground, already at play in the preceding phase. becomes intensified, being now, according to the estimate by Carlet., ${ }^{16}$ one-fifth in excess of the body weight. The pressure is now at the ball of the foot exclusively, and in my experiments, at the sesamoid bones of the inner metatarsal, where the air-bulb for the ball of the foot was placed. The associated movements in the other segments of the limbs during this phase are: The homolateral hip is markedly extending, the knee is also markedly extending, the quadriceps cruris is contracting and the quadriceps of the contralateral limb, which is at this time returning to the ground (phase $f^{\prime}$ ), is also contracting. (4) Phase $d$, which represents the period when the limb exerts pressure on the ground by the toes only. The pressure on the ground at the toes causes some compression of the air-bulb at the ball of the foot. and is thus recorded by a partial elevation in the curve of the record. During this phase the homolateral hip is markedly extended, the knee is markedly flexed, the quadriceps is relaxed and the quadriceps in the contralateral limb, at this time in phases $a^{\prime}$ and $b^{\prime}$, is contracted. $d$ terminates the period during which the foot is in contact with the ground, and is followed by (5) $e$, which corresponds to the time during which the foot is in the air and advancing. The movements in the other segments of the limbs during phase $c$ are: The hip is flexing, the knee continues to be in flexion, the quadriceps is relaxing and the quadriceps of the contralateral limb, at this time in phase $b^{\prime}$, is contracting. (6) $e$ is followed by phase $f$, when the limb is returning to the ground. During this phase the homolateral hip is slightly extending, the knee is extending, the quadriceps is contracting and the quadriceps of the other limb, at this time in phase $c^{\prime}$, and exerting pressure on the ground by the ball of the foot, is also contracting. It will be seen thus that a complete step is composed of six different and distinct phases, four of these phases forming the propulsion period of the step and two more the period when the foot is in the air.

On looking now at the phases of the step for the combination of movements, which is observed to occur synchronously with the Babinski sign, we find that it is reproduced in phases $a$ and $b$, when the body is exerting pressure on the ground mainly at the heel. During this phase of the step, the following movements take place: The big toe becomes dorsiflexed on the foot; the other toes, as shown by Pettigrew, ${ }^{13}$ spread out and generally undergo plantar flexion; the whole foot from the direction of movement of the body and limb, which is not only forward, but as shown by Pettigrew and Morey,

16. Carlet, G.: Ann. d. sc. naturelles 16:5, 1872. 
also horizontally outward, becomes everted; the knee is slightly flexed; the quadriceps cruris and the gluteus maximus are in contraction, and the quadriceps of the contralateral limb, at this time exerting pressure on the ground by the toes (phase $d^{\prime}$ ), is relaxed.

THE PHYSTOLOGIC SIGNIFICANCE OF THE BABINSKI TOE RESPONSE

The following theory thus suggests itself. It may be assumed (Marie and Foix) that the function of progression. is represented in the spinal cord (l' automotisme medullaire) ; that normally the movements of progression are kept more or less in check by inhibitory influences of the cerebrum. When, however, inhibition from the cerebrum is cut off as a result of disease of the corticospinal tracts, the spinal centers of progression reassert themselves whenever a stimulus reaches them from the limbs, and the stimulated limb or both limbs execute the stepping reflex in a minor degree. The stepping reflex exhibits itself in the Babinski toe response which represents phase $b$, the first and most important phase in the propulsion period of the step. Phase $b$ is the only manifestation of the reflex when the stimulus is mild. When the stimulus is intense, the stepping reflex reaches a much wider extent and passes through, to a minor degree, also phase $d$. The quadriceps cruris of this limb, in contraction in phase $b$, thus becomes relaxed, and there is usually at the same time a movement of plantar flexion of the big toe following the original dorsiflexion. A pronounced reflex of this type affects also the contralateral limb, and, while the stimulated limb is in phase $d$, the quadriceps of the former limb contracts. The most striking features of the Babinski toe response are, the dorsiflexion of the big toe, the spreading out of the lesser toes and the eversion of the foot. This is probably due to the close proximity of the muscles involved in these movements to the point of application of the stimulus (the plantar surface of the foot). If, however, the reflexogenous zone (of the Babinski toe response) extends over the entire limb, (and occasionally also the lower part of the abdomen) the stimulus when applied to the upper part of the limb may, as noted by Marie and Foix, produce extension of the limb (marked action of the gluteus maximus and the quadriceps cruris) and no dorsiflexion of the big toe. The effect of the stimulus is in this instance, too, produced chiefly on the muscles close to the point of stimulus and not on the parts distal to it.

This theory of the Babinski sign explains also the so-called crossed plantar response, frequently observed in paraplegia and occasionally in hemiplegia, which consists of plantar flexion of all the toes with extension of the foot. The phenomenon has been studied and inter- 
preted in various ways by Byron Bramwell, ${ }^{17}$ Knapp, ${ }^{4}$ Fairbanks ${ }^{18}$ and others. If the Babinski toe response represents the propelling period of the step that occurs in phase $b$, the contralateral limb at this time being in phase $d^{\prime}$, the effect of the stimulus to one limb, when the.irritability of the nervous system is so great that the reflex affects the other limb also, must be that of plantar flexion of all the toes in the latter limb, the foot being at the same time fully extended at the ankle. Frequent absence of the crossed plantar response may be accounted for by the remoteness of the toes in the nonstimulated limb from the point of application of the stimulus.

This theory may also explain why the Babinski toe response, while obtainable in some conditions by a stimulus applied to any part of the limb and even the lower part of the abdomen, is obtained with such marked facility by pressure at certain foci in the foot and leg. These "receptive foci" are, I believe, the heel, the ball of the foot and the area under the outer malleolus. It will be noted that pressure at the heel and the ball of the foot reproduces the condition which is associated with dorsiflexion of the big toe in walking, and that pressure under the outer malleolus produces an effect on the peroneus longus, the existence of which is, as stated by Huxley, ${ }^{19}$ absolutely distinctive of the human foot, a muscle that is essentially an organ of locomotion.

25 East Washington Street.

17. Bramwell, Byron: Rev. Neurol. \& Psychiat. 1:795, 1903 ; ibid. 9:49, 1911.

18. Fairbanks, A. W.: Rev. Neurol. \& Psychiat. 9:225, 1911.

19. Huxley, T. H.: Man's Place in Nature, New York. O. Appleton \& Co., 1896, p. 124. 